\title{
Effect of Ambient Temperature on Solid Motor Grain in Shipboard Multi-launch Container
}

\author{
Jin-Fei $\mathrm{LI}^{1, a,{ }^{*}, \text { Wei-Dong HUANG }}{ }^{1, b}$, Ming YANG ${ }^{1, c}$, Yi-Jun CAO ${ }^{1, d}$ \\ ${ }^{1}$ Department of Aircraft Engineering, Naval Aeronautical and Astronautical University, 264001, \\ Yantai, China \\ alijinfei_03@163.com, bwdhuang103@yahoo.com, ctomorrowyoung@163.com, \\ Yijun_123@163.com
}

Keywords: Propellant Grain, Thermal Stress, Ambient Temperature, Shipboard.

\begin{abstract}
In order to study the effects of shipboard environment on solid motor grain, the ambient temperature in multi-launch containers were monitored. The temperature and stress fields of solid propellant grain under different ambient temperature were obtained using three-dimensional viscoelastic finite element method. It is shown by the results that the changed trend of temperature, stress and strain of motors in multi-container is similar to the environment temperature. The stress and strain were largest at the star tip of grain, and the stress and strain were closer in the upper and bottom layer containers.
\end{abstract}

\section{Introduction}

Due to the simple geometry framework, conveniences of using and maintenance and long-time storage, the solid rocket motor is the dominated power device of shipboard missile. Different from the condition in depot that the temperature and humidity is constant, the shipboard missiles in multi-launch container suffer high temper in the summer, freeze-up in the winter and vibration caused by ocean wave. As a result of the great different of expand ratio between shell and grain and the influence of the alternate changed environment temperature when shipboard, the stress and strain were brought in the motor. Especially, the fatigue damage in the cohesive interface and propellant caused by thermal stress can lead to crack and debonding, and then the Structural Integrality of motor is broken down ${ }^{[1-5]}$. Under the influence of wind and sunshine, the temperature in multi-launch containers of upper and bottom layer is distinct. The Monitored ambient temperature in the containers and calculated the temperature and stress distribution can provide data for maintenance and service evaluation of shipboard solid motor.

In this paper, based on the conduction model, the viscoelastics constitutive relationship and the ambient temperature in multi-launch containers of upper and bottom layer, the temperature and stress field were calculated by finite element method, and the easier disabled position of solid motor was presented.

\section{Theoretic Model}

\section{Transient Heat Conduction Model}

When the conduction ratio along different direction is constant, the isotropic continuum medium heat exchange differential equation is given below ${ }^{[6]}$ :

$$
\lambda\left(\frac{\partial^{2} T}{\partial x^{2}}+\frac{\partial^{2} T}{\partial y^{2}}+\frac{\partial^{2} T}{\partial z^{2}}\right)=\rho c \frac{\partial T}{\partial t}
$$

Where the $\lambda$ is the conductivity ratio, $\rho$ is the density, $c$ is the specific heat. 


\section{Thermal Viscoelastics Equation}

Assuming that the solid propellant is the simple isotropic thermal material, the integral thermal viscoelastics relationship of motor grain shows in the Eq. $2^{[7,8]}$ :

$$
\begin{aligned}
& S_{i j}(t)=2 \int_{-\infty}^{t} G\left(\xi-\xi^{\prime}\right) \frac{\partial e_{i j}(\tau)}{\partial \tau} d \tau \\
& \sigma_{k k}(t)=3 \int_{-\infty}^{t} K\left(\xi-\xi^{\prime}\right) \frac{\partial}{\partial \tau}\left[\varepsilon_{k k}(\tau)-3 \alpha \theta(\tau)\right] d \tau
\end{aligned}
$$

Where the $\alpha$ is the linear expansion coefficient, $\theta(\tau)$ is relative transform value; $G(t)$ and $K(t)$ is the shear and bulk modulus, and they are the function of equivalent times $\xi$ and $\xi^{\prime}, \xi$ and $\xi^{\prime}$ can be calculated as below:

$$
\xi=\int_{0}^{t} \frac{d \tau}{\alpha_{T}(T(\tau))}, \xi^{\prime}=\int_{0}^{t^{\prime}} \frac{d \tau}{\alpha_{T}(T(\tau))}
$$

Where the $\alpha_{T}$ is the time-temperature conversion factor, it can be acquired by W.L.F equation as below:

$$
\lg \alpha_{T}=\frac{-c_{1}\left(T-T_{r e f}\right)}{c_{2}+T-T_{r e f}}
$$

Where the $T_{r e f}$ is the referred temperature, $c_{1}$ and $c_{2}$ are the constants that need to determine.

\section{Material Parameter and Geometry Model}

\section{Material Parameter}

The studied motor grain is HTPB composite propellant, the free stress temperature is $60^{\circ} \mathrm{C}$, the prony progression of relaxation modulus of propellant is given below:

$$
E(t)=1.175+1.386 e^{-20 t / \alpha_{T}}+2.146 e^{-2 t / \alpha_{T}}+3.501 e^{-0.2 t / \alpha_{T}}+3.984 e^{-0.02 t / \alpha_{T}}
$$

When $T_{r e f}$ is $20^{\circ} \mathrm{C}, c_{1}$ and $c_{2}$ are 22.5 and 353.7 and the $\alpha_{T}$ can be obtained by Eq.4.

The parameter of the motor shell, underlayer and grain are presented in table 1 . The package sleeve is plastic material, and its Poisson ratio is 0.3 , and the other's parameter are similar to underlayer.

Tab.1 Material Parameter

\begin{tabular}{c|c|c|c}
\hline Properties & Shell & Underlayer & Propellant \\
\hline Density $\mathrm{kg} \cdot \mathrm{m}^{-3}()$ & 7850 & 1280 & 1700 \\
\hline Specific heat $\left(\mathrm{J} \cdot \mathrm{kg}^{-1} \cdot \mathrm{k}^{-1}\right)$ & 512.91 & 2200 & 1140 \\
\hline $\begin{array}{c}\text { Heat conduction ratio } \\
\left(\mathrm{W} \cdot \mathrm{m}^{-1} \cdot \mathrm{k}^{-1}\right)\end{array}$ & 38.95 & 0.0556 & 0.57 \\
\hline Expansion ratio $\left(\mathrm{K}^{-1}\right)$ & $1.05 \times 10^{-5}$ & $9.2 \times 10^{-5}$ & $9.2 \times 10^{-5}$ \\
\hline Poisson ratio & 0.3 & 0.495 & 0.495 \\
\hline Elastic modulus $(\mathrm{MPa})$ & $2.06 \times 10^{5}$ & 4 & $\mathrm{E}(\mathrm{t})$ \\
\hline
\end{tabular}




\section{Mesh}

Because of the symmetrical framework, 1/10 model was selected to study. The C3D8T element was applied to finite element scattering, such as shell, underlayer and the package sleeve. and the C3D4T element was used in grain dispersing. The grain meshed by freedom grid, and the others meshed by sweep grid. The finite element grid model of motor showed in Fig.1.

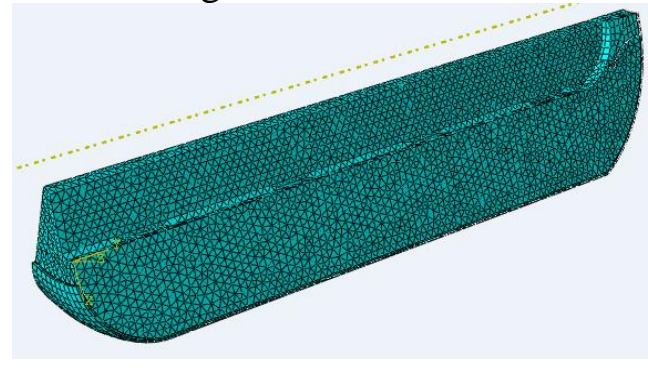

Fig.1 Grid model

\section{Initial and Boundary Condition}

The symmetrical restriction was inflicted to the symmetry plane when calculated, the outside shell of motor was chosen to temperature verge, where the monitored temperature will act on. The outside shell was fixed, while the internal surface of motor was free.

\section{Results and Analysis}

To describe the influence of ambient temperature on motor, four key points were selected. The point $\mathrm{A}$ is No.19 node, which located in the joint between the tip of motor head and the package sleeve. The point B is No.538 node, which located in the tip of middle of motor. The point C is No.781 node, which located in the joint between tail of grain and under layer. The point D is No.3 node, which located in the tip of motor tail. The location of four missile motors was showed in Fig.2.

\begin{tabular}{|c|c|c|}
\hline Upper & $1 \#$ & $3 \#$ \\
\hline Bottom & $2 \#$ & $4 \#$ \\
\hline
\end{tabular}

Fig. 2 The Location of Motor in Containers

\section{The Temperature Field}

The temperature distribution contour of the motor in warming process showed in Fig.3(a), and the temperature value decreased from outside shell to interior, at the meantime, the internal temperature of motor in upper container is higher than the bottom. The cooling process of motor showed in Fig.3(b), on the contrary, the highest temperature of motor located at the star tip. The highest temperature in motors of upper and bottom layer have a little of differences, but the lowest located in the upper.

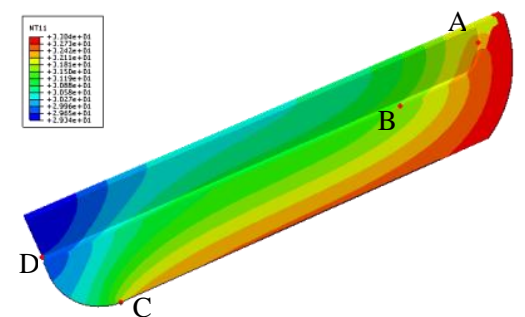

(a) The Warming Process

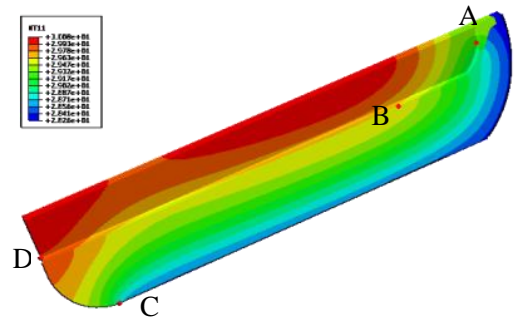

(b) The Cooling Process

Fig. 3 The Temperature Field of Motor 1\# 
The temperature curves of the key points showed in Fig.4. For the distance from point A and B to the shell is similar, the temperature value has small variety, so the point A was not signed in Fig.4(a). It is indicated that the temperature of point $C$ changed seriously than others and the peak value is the biggest, and the reason is that the point $\mathrm{C}$ is near to the shell, and the conduction rate is fast. What's more, the grain has the bad performance of heat transfer, when the heat energy transfer to the internal, the ambient temperature is cut down, so the temperature of star tip of motor is the smallest and the peak time is lagged.

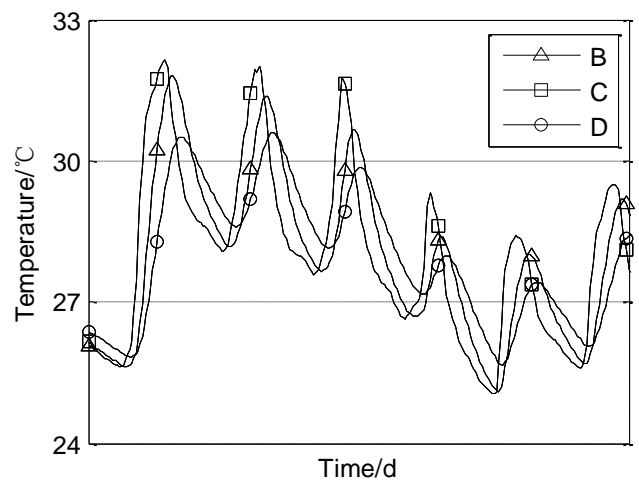

(a) The Key Point in Motor 1\#

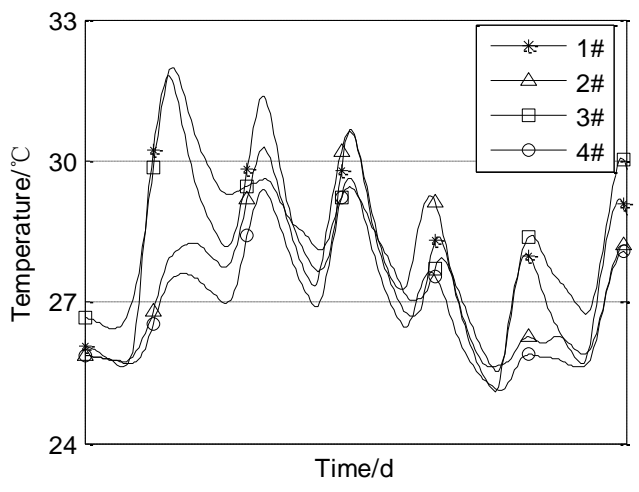

(b) The Key Point B of Four Motors

Fig.4 The Temperature Curves of the Key Point

\section{The Stress Field}

The stress distribution contour of the motor showed in Fig.4. In warming process, the temperature of the motor $1 \#$ is bigger, the thermal stress is $0.1295 \mathrm{MPa}$, while in cooling process the temperature is lower and the thermal stress is $0.1426 \mathrm{MPa}$. It can be known that whether in warming or cooling process, the thermal stress located in the tip of middle of motor is biggest and the root of motor is zero. Because the package sleeve and artifactitious debonding layer can release the axial stress, the thermal stress of point B is greater than the point $A$ at the same temperature.

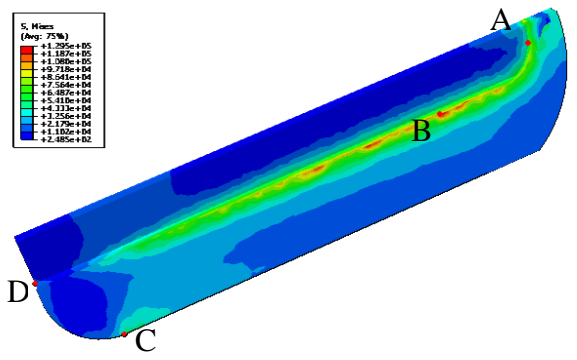

(a) The Warming Process

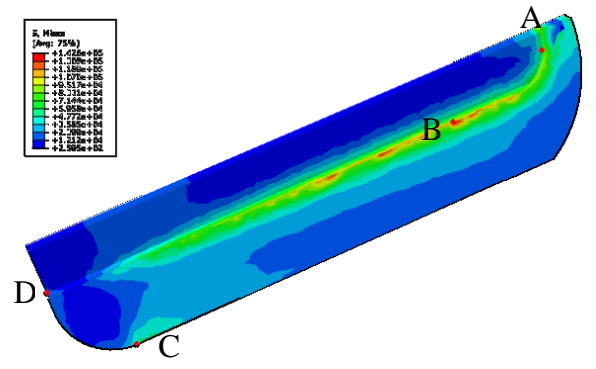

(b) The Cooling Process

Fig.5 The Stress Field of Motor 1\#

The thermal stress curves of key points in motor 1\# showed in Fig.6(a), it can be seen that the thermal stress of point $\mathrm{D}$ is a little and the point $\mathrm{B}$ is the biggest, because the location of point $\mathrm{D}$ is without constraint. For the axial stress reduced from the head to the middle of motor, the stress of point $\mathrm{B}$ is bigger than point $\mathrm{A}$. As a result of the great range of temperature in upper layer, the amplitude of stress in upper motor is bigger than the bottom. The maximum stress of motor appeared in bottom layer because of the cold ambient temperature. 


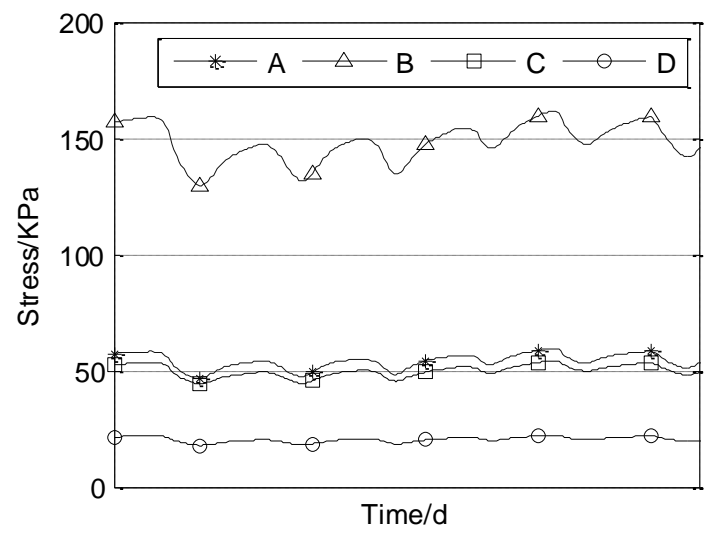

(a) The Key Point in 1\# Motor

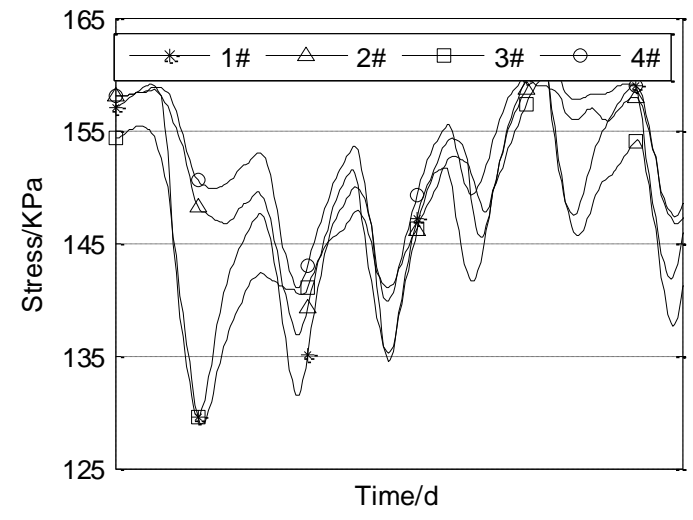

(b) The Key Point B of Four Motors

Fig.6 The Temperature Curves of the Key Point

\section{The Strain Field}

The distribution of strain in the warming and cooling process are uniform, the changed factor is only the value. The strain curves of the key points in motor 1\# presented in Fig.7(a). It can be seen that the strain of point $\mathrm{D}$ is almost near to zero and the strain of point $\mathrm{B}$ is the biggest. The peak value of strain of motor in upper and bottom layer is accordant, while the minimum value of the upper motor is greater than the bottom. The strain curves of point B in four motors laid out in Fig.7(b). It indicates that the strain curve of point B is opposite to the stress's, the maximum value of strain came under the least thermal stress, and the strain amplitude of point B in upper layer is bigger than the bottom.

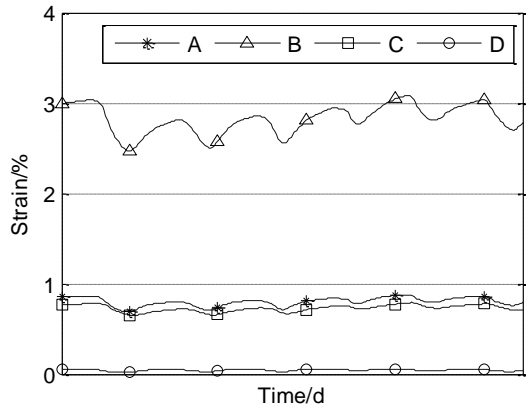

(a) The Key Point in 1\# Motor

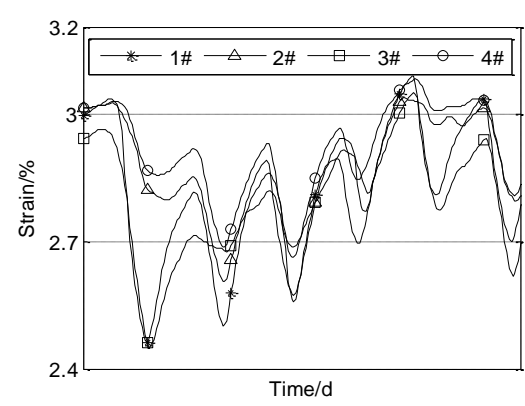

(b) The Key Point B of Four Motor

Fig.7 The Strain Curves of the Key Point

\section{Summary}

First, the high temperature of motor in containers are smaller than the ambient and the low temperature of motors are bigger than the environmental. The mean temperature of motors in bottom layer are more little than the upper layer's, while the stress and strain are on the contrary.

Second, the changed trend of temperature, stress and strain of motors in multi-container is similar to the environment temperature. The cracks will appear at the tip of middle of motor where the thermal stress is the biggest, the connected place located between the tail and the cylindrical part of motor is easier to debonding.

\section{References}

[1] Kratzsch K A. Munitions health monitoring-evaluation of ammuniti on load data gathered under operational conditions. RTO-MP-AVT-176-28. 
[2] Hong-yan LIU, Guo-bao LI. Heat transfer analysis of solid motor on the environmental temperature in warship. J. Tactical Missile Technology, 1(2011) 44-48.

[3] PAN Wen-geng, WANG Xiao-ming, CHEN Rui,etc. Efect of environmental temperature on storage rocket motor grain. J. Nanjing University of Science and Technology. 33(2009) 17-121.

[4] Richard K Kunz. Characterization of solid propellant for linear cumulative damage modeling. AIAA(2009)4973-4979.

[5] Richard K Kunz. Continuum damage mechanics modeling of solid propellant. AIAA(2008) 4968-4973.

[6] ZHEN ya, CHEN jun, JU yu-tao, etc. Heat transfer of solid rocket motor. Beijing university of aeronautics and astronautics Press, Beijing, 2006.

[7] Heller R A, Singh M P, Zibdeh H. et al. Environmental effects on cumulative damage in rocket motors. J. Spacecraft, 22(1985) 149-155.

[8] Zhi-chun ZHU. Study on life prediction of SRM grain structure. Beijing university of aeronautics and astronautics, Beijing, 1997. 